\title{
O QUe é Pensamento CIENTÍFICO EM QUÍMICA?
}

REIKO ISUYAMA ${ }^{1}$

A química é uma ciência baseada fortemente em observações experimentais. Muitas evidências experimentais ainda não estão fundamentadas de forma totalmente lógica. Em várias situações o raciocínio lógico não encontra respaldo nos dados experimentais. Alunos que têm capacidade de raciocinar de forma lógica muito aguçada percebem que, dentro da química, há etapas no raciocínio lógico que não há conexões. Esta é uma das grandes dificuldades do ensino de química.

Qualquer pessoa já deve ter ouvido um professor dizer: "este aluno não sabe pensar". Na realidade o que esse professor quer dizer é que esse aluno não sabe usar os conhecimentos que ele tem e estruturar um processo mental lógico. Esse processo é complexo e por isso requer uma estratégia especial de ensino. A química dentre as ciências é uma das mais apropriadas para o exercício deste tipo de raciocínio, por tratar de sistemas simples onde as causas e os efeitos são facilmente perceptíveis.

O pensamento científico requer o desenvolvimento de uma boa dose de raciocínio formal, mas o fato do estudante ter o raciocínio abstrato desenvolvido não é garantia de que as implicações lógicas de

\footnotetext{
' Professora do Instituto de Química da Universidade de São Paulo.
} 
perguntas e respostas necessárias para resolver problemas científicos sejam também desenvolvidas. Segundo Lawson, o raciocínio formal usado pelos estudantes para estabelecer a conexão entre os questionamentos e as respostas parece ser independente da capacidade de verificar hipóteses (1). Além disso parece haver uma série de fatores externos ao processo do raciocínio lógico que dirige a maneira como nós usamos a capacidade lógica.

No desenvolvimento do raciocínio formal, uma pessoa considera uma hipótese a ser comprovada quando ela satisfaz uma implicação dupla: se $x$ tem relação com $y$, então, y deve ter relação $\operatorname{com} x$. Mesmo do ponto de vista lógico isso não é uma verdade. Este é um ponto onde os estudantes encontram muitas dificuldades. Têm dificuldade em perceber que há situações em que, apesar de $x$ ter relação com $y$, não se pode afirmar que y tem relação com $x$. Os diagramas a seguir mostram exemplos de situações em que não se observam essas relações. Supondo que os círculos representam o universo de conhecimentos atuais sobre $\mathrm{x}$ e $\mathrm{y}$, há duas situações nas quais a relação entre $\mathrm{x}$ e y não são satisfeitas:

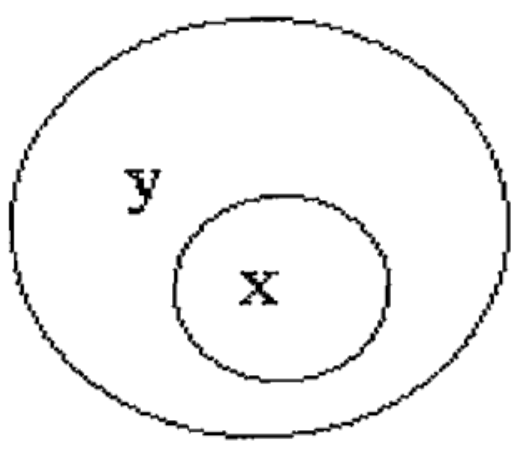

Figura 1a: $x$ tem relação com y mas existem partes de y que não têm relação com $x$. 


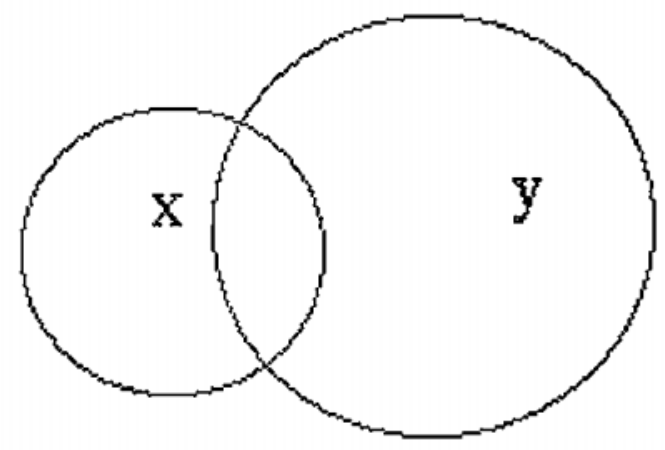

Figura 1b: Existem partes de x e de y que não têm relação.

Para que a pessoa consiga perceber a existência dessas situações em que apesar de $\mathrm{x}$ ter relação com $\mathrm{y}$, nem todo $\mathrm{y}$ tem relação com $x$, é preciso que esta pessoa tenha um conhecimento abrangente e profundo de $x$ e de $y$.

Se o conhecimento da pessoa sobre y for restrito, ela não conseguirá pensar situações em que y não tem relação com x. Neste caso a pessoa concluirá que se $\mathrm{x}$ tem relação com $\mathrm{y}$, então, $\mathrm{y}$ tem relação com $x$, porque não terá conhecimentos de fatos ou de situações em que isto não acontece.

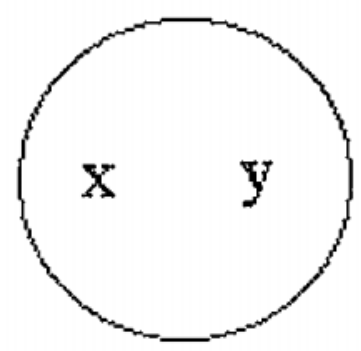

O raciocínio científico é complexo porque envolve o pensar nas múltiplas implicações lógicas considerando como base de raciocínio os dados experimentais. 
A complexidade do raciocínio se torna maior quando se considera a multiplicidade de fatores que influem nesta relação. A presença de múltiplos fatores nos obriga a considerar os efeitos de cada um deles. É muito mais fácil verificar uma hipótese num contexto em que se está acostumado a pensar e obter o máximo de informações seguindo este raciocínio em vez de raciocinar considerando hipóteses desconhecidas.

A nossa capacidade de chegar a uma conclusão depende da habilidade de manipular hipóteses redundantes sobre informações (dados experimentais) que não sejam contraditórias e não, seguindo uma estrutura de raciocínio lógico envolvendo as poucas etapas possíveis. Processar um raciocínio lógico sem uma referência experimental é muito difícil mesmo para pessoas que têm capacidade de raciocínio formal muito desenvolvido. Chega-se então à conclusão de que o ensino de ciências, e o de química em particular, se torna muito mais eficiente se a capacidade de raciocinar for considerada não como uma habilidade característica de uma pessoa, como é comumente tratado, mas como uma habilidade que pode ser desenvolvida por meio de exercícios apropriados. A capacidade de efetuar as operações necessárias para aprender ciências está, como muitos pesquisadores têm mostrado, ligado de perto à capacidade de pensar de forma lógica que, por outro lado, pode ser desenvolvido por meio do ensino de ciências. Por outro lado, a capacidade de efetuar um raciocínio lógico pode ser desenvolvido por meio do ensino de ciências.

Não há uma série de operações lógicas especiais para ciências ou para matemática ou para estudos sociais, é possível entender que o desenvolvimento do raciocínio lógico, da qual o raciocínio científico é parte, é uma questão interdisciplinar. 


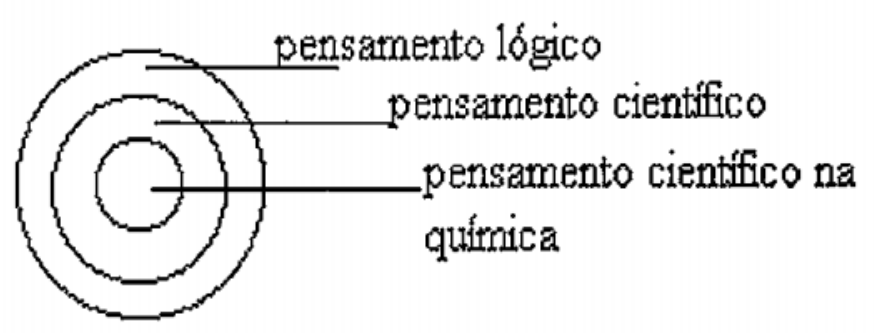

Portanto, esta questão, desenvolvimento do raciocínio lógico, deve unir os professores de diferentes áreas na busca de métodos que nos permitam entender, no contexto de cada área, o processo lógico que um estudante segue quando ele "sabe como pensar" ou quando ele não sabe pensar.

\section{Raciocínio lógico na química}

De acordo com Herron (2), Lawson (3) e Mc Cubbin (4), no ensino de química ou de uma outra ciência baseada em laboratório, a participação direta de estudantes nos experimentos estabelece um mecanismo de ação lógico cognitivo diferente daquele que se estabelece quando o ensino se restringe a uma comunicação apenas verbal. As aulas de química, portanto, nos oferecem uma oportunidade de analisar os processos de raciocínio lógico dos estudantes numa situação na qual o uso do laboratório é parte natural das atividades de ensino.

As atividades no laboratório, no entanto, não devem ser super estimadas como oportunidades para o desenvolvimento do processo lógico. Freqüentemente as atividades do laboratório ajudam a esclarecer e a aprofundar conceitos de química abstratos. Mas, isto só acontece se as experiências forem conduzidas de forma racional e sistemática. Para que os dados experimentais sejam compreensíveis, eles devem ser apresentados de forma que haja uma lógica entre as relações causa-efeito desses dados com outros fatos. 
Por outro lado, uma comprovação puramente lógica de uma proposição não garante a sua verdade, é preciso uma comprovação empírica. Portanto, é a partir de uma relação entre operações lógicas e fatos experimentais que a atividade de um laboratório adquire valor. Assim, quando apresentamos uma explicação devemos nos referir a um dado experimental de tal modo que os estudantes se acostumem a verificar a validade da explicação com base na sua compatibilidade com os dados reais.

Por exemplo, a composição do ar atmosférico é $80 \%$ de nitrogênio e $20 \%$ de oxigênio, enquanto a crosta terrestre é composta de $50 \%$ de oxigênio e $0,0019 \%$ de nitrogênio. Por que existe esta discrepância na composição do ar e da crosta terrestre se os dois sistemas estão em contato? Para buscar a resposta a esta pergunta, lança-se mão de hipóteses que devem ter uma conexão lógica entre elas. A explicação deve também considerar a consistência com outros dados experimentais disponíveis.

Foi verificado o comportamento de alguns estudantes frente a um problema, cuja solução requer a aplicação de um raciocínio lógico que liga os dados experimentais com as interpretações.

O relato a seguir se baseia em observações de um teste aplicado a um grupo pequeno de estudantes, para analisar o nível de desenvolvimento do pensamento científico.

As armaduras dos antigos guerreiros eram feitas de ferro e tinham uma aparência azulada, diferente da aparência do ferro. Para conseguir este efeito as armaduras eram queimadas ao ar.

\section{Descrição de um fato experimental:}

\section{Passando ar atmosférico sobre ferro aquecido, com uma chama de bico de Bunsen, observa-se a formação de um sólido azulado na superfície do metal.}




\section{Possíveis explicações:}

A) $\mathrm{O}$ ar atmosférico contém uma substância que se combina com o ferro quente formando um sólido azulado.

B) $O$ ferro quente é azul.

C) Nitrogênio e oxigênio do ar reagem à quente dando uma nova substância que se combina com o ferro formando o sólido azulado.

D) $\mathrm{O}$ ferro forma sólido azulado sempre que reage com uma outra substância.

\section{Observações experimentais:}

1. Se recolhermos o ar, depois de passar pelo ferro quente, vemos que ele não alimenta mais o fogo.

2. Se o gás recolhido após passar pelo ferro quente for passado por uma nova amostra de ferro, não há formação de sólido azulado.

3. Se for colocada uma vela acesa num recipiente fechado contendo o gás recolhido depois da queima do ferro, a vela se apaga imediatamente.

4. Se o ferro for aquecido dentro de um recipiente à vácuo, não se observa a formação de sólido azulado.

5. Não se observa nenhuma mudança aquecendo ar atmosférico contido num frasco.

As quatro explicações possíveis do fato experimental a respeito da transformação do ferro pelo aquecimento ao ar devem ser comparadas com os cinco dados experimentais descritos para ver se surgem contradições entre a explicação e os dados. Somente uma explicação (A) é a logicamente compatível com todo $s$ os dados experimentais e deve ser escolhida como a explicação correta.

$\mathrm{Na}$ escollha deste problema, foram seguidos alguns critérios que limitaram a influência de fatores externos. Assim, foi escolhido um contexto experimental, que fosse independente do conhecimento de outros fatos experimentais, para evitar a influência da falta de aulas 
experimentais sistemáticas nas nossas escolas. Além disso, o problema envolve uma relação típica de causa-efeito que facilita o raciocínio lógico. Alguns dados experimentais apresentados são de conhecimento dos estudantes, mesmo que eles não tenham elaborado explicações científicas a respeito desses dados. É possível verificar a consistência entre a conecção lógica usada para resolver o problema e a explicação escolhida, se o estudante conseguir mostrar o raciocínio utilizado para chegar na sua escolha.

Alguns alunos que escolheram a explicação correta, apesar de não fazerem conexões com os dados experimentais. Estes estudantes mostram que há uma tendência de ignorar o uso da lógica para resolver um problema. Procura se basear em informações previamente adquiridas na escola ou em algum outro lugar. Esta postura é problemática se considerarmos que o acerto se torna casual uma vez que o conhecimento prévio do assunto pode estar correto ou não. Se acontecer do conhecimento utilizado ter sofrido distorção durante o processo de armazenamento, a escolha da explicação será errada. A escolha de uma explicação baseada em conhecimento prévio, ignorando os dados disponíveis é uma postura anti-científica muito comum entre os estudantes.

Segundo Kempa (5), os estudantes usam conhecimentos previamente adquiridos na escola ou na vida diária em vez do raciocínio lógico. Este dado mostra que a capacidade de raciocínio lógico dos estudantes não está ligado à habilidade de pensar de forma lógica mas é fortemente influenciado pelas informações prévias adquiridas na escola em suas experiências pessoais.

Há, por outro lado, estudantes que tentaram fazer uma análise lógica dos fatos experimentais, mas se perderam na complexidade do raciocínio e optaram por concluir baseado só nas etapas iniciais do raciocínio lógico. São estudantes que identificaram a conexão lógica entre fatos individuais mas, năo foram capazes de usar estas conexões para escolher a explicação final.

Há também uma terceira categoria de estudantes que, apesar de identificarem as incompatibilidades dos dados experimentais com as explicações, escolheram a resposta certa, mas são incapazes de explicar de forma lógica a escolha feita. Isto mostra que, mesmo estes estudantes que percebem as inconsistências entre fato experimental e 
explicações, não conseguem desenvolver o processo lógico da escolha da explicação.

Apesar do número de estudantes submetidos a esta investigação ter sido muito pequeno e por isso não permitir um estudo estatístico, foi perceptível que a maioria dos estudantes justificou a escolha da explicação com base nos conhecimentos prévios e não nas incompatibilidades entre os dados experimentais e as interpretações. Esta observação nos leva a concluir que quando um estudante tem dificuldade em raciocinar de forma lógica, ele procura usar conhecimentos prévios adquiridos. Foi possível observar que os estudantes que agiram desta forma eram aqueles que tinham melhor conhecimento de fatos químicos que os outros, o que parece tê-los confundido. Há necessidade de se atingir um equilíbrio entre informações e o processo de manipulação lógica dos dados.

Mc Cubbin afirma (4) que se pode-se tirar uma conclusão mais geral, de que a abordagem lógico-experimental é pouco valorizada no ensino de química ou que, devido à forma como são ministradas as aulas, principalmente as experimentais, onde os alunos comprovam fatos já apresentados pelo professor nas aulas teóricas, não desenvolvem este tipo de lógica.

Há necessidade de se prestar mais atenção à questão da lógica no ensino de ciências e no ensino de química em particular, tanto em nível de estrutura curricular quanto na estrutura de um assunto específico.

Esta habilidade deve ser desenvolvida por meio de vários processos lógicos que um estudante deve seguir para explicar os fatos experimentais no contexto da química e assim, chegar a uma compreensão clara desta disciplina. No ensino da química é muito comum darmos saltos no raciocínio lógico. Usamos o processo indutivo/dedutivo quando passamos da observação de um fenômeno para a sua explicação ou quando aplicamos uma teoria geral na compreensão de um fato cspecífico, sem estabelecer o contexto detalhado do problema. Estes saltos que damos no raciocínio fazem com que os estudantes tenham dificuldade em adquirir a habilidade de raciocinar com precisão e, em particular, de fazer a ligação entre as informações teóricas com os dados experimentais, numa base lógica. 
Por exemplo, no dado experimental sobre a composição do ar e da crosta terrestre, o professor pode dar um salto no raciocínio e concluir que o nitrogênio é uma substância pouco reativa. Essa explicação é produto de um salto onde o professor não mostrou as etapas intermediárias do raciocínio e de outras evidências experimentais que deram base às etapas intermediárias. Esta, infelizmente é uma prática muito comum entre os professores que não detalham o processo do raciocínio seguido.

Outro problema é o uso, no ensino de química, de experiências com resultados garantidos e baseados numa explicação prévia, o que dificulta o desenvolvimento cognitivo. As experiências de química devem permitir a possibilidade de várias interpretações e dar ao estudante a oportunidade de examinar a confiabilidade da explicação, buscando a consistência com os dados experimentais. Este tipo de experiência promove tanto a aprendizagem do conteúdo científico quanto do método científico.

Parece-nos que um dos objetivos fundamentais do ensino de ciências é o de desenvolver no estudante a capacidade de enxergar analogias para que ele possa vencer a dificuldade de imaginar outras possibilidades e assim adquirir confiança de praticar este processo complexo de análise de dados e explicações por meio da aplicação de um raciocínio lógico.

\section{Referência bibliográfica:}

HERRON, J. D., Piaget in the classroom. Journal of Chemical Education. Vol. 55, pp 165-170.

KEMPA R. F.; NICHOLLS, C. E. Problem Solving Ability and cognitive structure. European Journal of Science Education, Vol 5, pp 171-184. 1983.

LAWSON et al. The acquisition of propositional logic and formal operational schema during the secondary school years. Journal of Research in Science Teaching. Vol. 15, pp 465-478. 
LAWSON, A. The acquisition of propositional logic and formal operational schema during the secondary school years. Journal of Research in Science Teaching. Vol 20, pp 347-356, 1978.

MC CUBBIN, W. L. The role of logic in students assessment of scientific explanations. European journal of Science Education. Vol 6, pp 67-77, 1984. 